\title{
SYMPOSIUM
}

\section{Procedural Justice in Online Deliberation: Theoretical Explanations and Empirical Findings}

\author{
Leanne Chang* and Weiyu Zhang ${ }^{\dagger}$
}

This article reviews extant conceptualizations of procedural justice and reports the results of an empirical study testing the effects of fair deliberation. From a communicative action perspective, we argue that Habermas's conceptions of speech conditions and validity conditions can be used to evaluate the discursive and substantive dimensions of procedural justice in deliberation. That is, fair deliberation is built on the fulfillment of discourse norms and the communicativeness of dialogic interactions. The communicative measures are compatible with extant procedural justice measures and provide a communication-centered ground for evaluating deliberative outcomes related to procedural justice. The case study involves public discussion of the Singaporean government's population policies on an online deliberative platform. The results show that when procedural justice is presented in the realization of both speech conditions and validity conditions, it fosters participants' beliefs in the rightfulness of deliberative policymaking. In addition, speech conditions play a more important role than validity conditions in predicting citizens' specific policy support after online deliberation. The findings illustrate one instance of how communicative norms are prioritized in different deliberative settings and what deliberative benefits a fair procedure can achieve. The results shed light on the theorization of procedural justice and advance the extant knowledge of evaluating procedural justice in deliberation.

Keywords: communicative action; fairness; Habermas; procedural justice; speech conditions; validity claims

\begin{abstract}
Introduction
Deliberation has demonstrated its normative importance and applicability in different institutional and issuespecific contexts (Curato et al. 2017). Researchers have outlined the benefits of deliberation, which include enhanced civic competence, increased public interest in political affairs, development of participatory knowledge and skills, proneness to collective action, and a more reflective decision-making process (Farrell, O'Malley \& Suiter 2013; Gastil, Deess \& Weiser 2002; Grönlund, Setälä $\&$ Herne 2010). Despite the shared notion of the normative and pragmatic value of deliberation, the questions of what constitutes good deliberation and according to what criteria good deliberative performance is achieved have induced unsettled disputes among deliberative theorists (Mansbridge et al. 2012; Owen \& Smith 2015).

This study examines the procedural justice aspect of deliberation to inform and evaluate elements that comprise good deliberation and underpin beneficial deliberative outcomes. From a proceduralist perspective, good deliberation lies in participants' recognition of a public discussion process as just and fair (Besley \& McComas
\end{abstract}

\footnotetext{
* Hong Kong Baptist University, HK

+ National University of Singapore, SG

Corresponding author: Leanne Chang (leannechang@hkbu.edu.hk)
}

2005; Zhang 2015). We argue that Habermas's (1979, $1984,1996)$ conceptions of speech conditions and validity conditions are key procedural justice principles applicable to the evaluation of the discursive and substantive dimensions of procedural justice in deliberation. Instead of treating deliberation as a unidimensional attendance variable with a yes/no response (e.g., the presence or absence of deliberation in political decision making), we propose that deliberative processes may vary in their degrees of fulfillment of procedural justice norms. For instance, citizens may take part in a political discussion on public affairs but may not perceive it to be deliberative due to unmet discourse rules and/or unsatisfactory claims to validity that curb open dialogue and mutual reason giving. Accordingly, a partial or complete lack of fulfillment of procedural justice norms may hamper the beneficial effects that good deliberation ought to generate.

We concur with Owen and Smith's (2015) critique of the systemic turn's emphasis on evaluating deliberation at the macrostructural level and posit that evaluation of quality deliberation must come from those who take part in the process. Inasmuch as reasonableness and accountability are the core of deliberative decision making (Chambers 2003; Curato et al. 2017; Delli Carpini, Cook \& Jacobs 2004), citizens' assessment of the deliberative process should be at the center, reflecting the quality of deliberation (Mercier \& Landemore 2012). 
To demonstrate the procedural justice approach to evaluating justice as fairness in deliberation, in this article we first review extant theoretical treatments of fair deliberation from a procedural justice perspective. The concept of procedural justice neither originated from, nor is unique to, deliberative democratic research. Hence, there is a need to review how procedural justice has been theorized and measured under different research traditions. Second, we test procedural justice in an online deliberation setting to investigate specified beneficial outcomes associated with fair deliberation.

\section{Theorizing Procedural Justice}

Modern discussions about procedural justice have a strong basis in Rawls's (1999) theory of justice, which defined justice as fairness and posited that a just procedure, in its perfect form, involves fair allocations of resources that meet the principles of equal opportunity and benefit the least-advantaged members of the society. The Rawlsian conception of procedural justice highlights that fair procedures ought to conform to moral values of liberty, equality, and inclusivity. Inasmuch as the object of Rawls' social contract is based on broad principles associated with constitutional essentials, his idea of procedural justice does not emphasize the practice of open dialogue and reason sharing in every instance of lawmaking (Dryzek 2000; McCarthy 1994). This is demonstrated in his thought experiment, 'the veil of ignorance,' which holds that procedural justice is rooted in an overlapping consensus on common human reason that requires rationality but not deliberation to achieve procedural justice.

After Rawls, two major approaches have been pursued to examine procedural justice in decision-making processes: the social psychological approach and the deliberative approach (Besley \& McComas 2005). The former guides empirical studies in exploring how and why decision making is perceived to be procedurally just in legal and organizational settings such as judicial hearings, contact with the police and the courts, and organizational management (Colquitt et al. 2001; Lind \& Tyler 1988; Tyler 2000). The latter provides theoretical analyses of fairness-related principles and derives procedural justice principles from deliberative norms (Cohen 1993; Dryzek 2000; Gutmann \& Thompson 2004). Notably, the social psychological approach has established more systematic measures of procedural justice, whereas the deliberative approach demonstrates a stronger focus on communication embedded in procedural justice judgments. We review studies from both camps to justify our proposal of using a communicative action approach for evaluating procedural justice in deliberation.

Justice scholars from the social psychological perspective have defined procedural justice in three ways: (1) procedural justice as having more individual control over the procedure (Thibaut et al. 1974); (2) procedural justice as having more accountable and responsive authorities to carry out resource allocations (Leventhal 1980); and (3) procedural justice as the authorities showing more effort to strengthen social bonds with group members (Lind \&
Tyler 1988; Tyler 2000). Corresponding evaluation criteria have been developed based on these definitions.

For instance, the Thibaut criteria promote the use of process control (i.e., the extent to which individuals perceive opportunities to present their points of view) and decision control (i.e., perceived opportunities to negotiate role positions) to assess the rightfulness of legal procedures and the impact on process satisfaction (Thibaut \& Walker 1978). The Leventhal criteria, which have been widely used to evaluate the perceived procedural justice of resource allocations in work organizations (Colquitt et al. 2001), consist of six subcriteria: the decision makers' consistent treatment of all affected parties; their efforts to suppress self-interested decision making and blind allegiance; the accuracy of their allocative performance; the correctability of their decisions; the representation of the concerns of all affected parties; and the ethicality of the authority's actions (Leventhal 1980). When executed properly, a procedure perceived as fair can enhance individuals' cooperative behaviors (Colquitt 2001; Gopinath \& Becker 2000). The relational model of justice emphasizes the relational base of procedural justice judgments (Tyler 1988, 1994, 1997, 2000). The feeling of being recognized as an in-group member and being treated with dignity and respect is central to individuals' evaluations of procedural justice. The relational model measures procedural justice according to four dimensions. Neutrality refers to the authority's proper and consistent application of rules. Trustworthiness involves group members' beliefs about the authority's intentions. Treatment with dignity and respect involves assessments of the interpersonal qualities of the authority's responsive behaviors. Opportunities for participation refers to perceived opportunities to present suggestions about allocative decisions (Hollander-Blumoff \& Tyler 2008; Tyler 2000).

Building upon the aforementioned criteria, political psychologists and management scholars have examined procedural justice in police and court encounters (e.g., Bradford 2011; Burdziej, Guzik \& Pilitowski 2019; Mazerolle et al. 2013; Reisig, Tankebe \& Mesko 2014;) as well as in supervisor-employee communication in the workplace (e.g., Colquitt 2001; Haas et al. 2015; Murphy \& Tyler 2008). Mainly applied to evaluate the authorities' allocative performance, however, these criteria of procedural justice are unable to capture key deliberative attributes, such as public reasoning, mutual justification, and ongoing dialogue about disagreements. This illustrates the need to develop more dialogue-centered measures reflective of procedural justice in deliberative processes (Besley 2010; Besley \& McComas 2005).

\section{Procedural Justice in Deliberation}

Deliberative theorists, particularly those interested in normative inquiries, have developed theses on how public discussions ought to operate and achieve political outcomes (Delli Carpini et al. 2004; Curato et al. 2017; Habermas 1996). Procedural justice has been concerned with principles such as equality, reciprocity, accountability, publicity, and inclusivity (Benhabib 1996; Dryzek 2000). Scholarly work suggests that procedural justice should underpin the flow of deliberation and form the basis of good deliberative performance. 
For instance, Cohen (2009) posited that ideal deliberative conditions should allow all parties equal opportunities to enter public spheres, exchange reasoning, enjoy equal standing during deliberations, and have an equal voice in decision making. No individual or group should be singled out during the process. In other words, the equality principle is emphasized. Gutmann and Thompson (1996, 2004) called for fulfilling the conditions of reciprocity, accountability, and publicity to realize procedural justice in deliberation. In their view, political discussions should involve mutual reason giving and mutual respect among all parties (reciprocity). Deliberation as an ongoing dialogic process should take place in public spaces and be open to all (publicity), and policymakers should be responsive to public concerns and inquiries (accountability). In addition to these conditions, deliberation should uphold participants' basic political rights, basic opportunities to make choices, and equal opportunities to be free from discrimination (equality). Thereafter, Young (2002) added to Gutmann and Thompson's claims and proposed that the inclusion of diverse voices, together with basic liberty, basic opportunity, and fair opportunity, are principles of justice in deliberative democracy.

Guided by these theoretical principles, a few researchers have examined procedural justice in deliberative settings. In these studies, procedural justice is characterized as the perceived rightfulness of the government's decisionmaking procedures (Herian et al. 2012), the extent to which a decision-making procedure leads to fair and reasonable plans (Birnbaum, Bodin \& Sandström 2015), citizens' perceived capacity to influence the decision outcomes (Grimes 2006), and the government's perceived fairness in interactions with (and responses to) citizens (Grimes 2006). These studies, however, either measured procedural justice with a single-item question (e.g., Herian et al.'s 2012 study of citizen assessments of a city government's budgeting processes in the United States), treated it as the 'outcome' of deliberation rather than examining the process attributes within deliberation (e.g., Birnbaum et al.'s 2015 study of government-citizen communication about ecosystem-based coastal zone management plans in Sweden), or assessed it without requiring citizens' direct participation (e.g., Grimes' 2006 study of the Swedish government's communication about the revitalized national railway system in mediated public spheres). These approaches to procedural justice examine the accountability aspect of procedural justice and are useful in revealing the relationship between the perceived procedural justice of government actions and institutional legitimacy. More research could, however, be done to advance theory-derived measures permitting a more comprehensive investigation of the various facets of procedural justice norms in deliberation.

Altogether, our review of the extant literature suggests that more theory-grounded criteria for procedural justice would be welcomed and that they should center on dialogue when the relevant contexts involve deliberation. Thus, we apply Habermas's (1979, 1984, 1990, 1991, 1996) discourse theory to identify two sets of normative conditions-speech conditions and validity conditions-to evaluate the perceived procedural justice of deliberation. Speech conditions define discourse ethics, and validity conditions reflect interpersonal connections. The two sets of conditions capture the communicative grounds of procedural justice judgments, yet they are compatible with extant procedural justice measures.

\section{The Communicative Action Approach}

Habermas's contributions to the theorization of deliberative democracy are undoubtedly immense. His theses on communicative action and discourse norms have shaped the deliberative understanding of democratic politics (Cohen 2009; Gutmann \& Thompson 2004). From a Habermasian (1996) perspective, deliberation is an inseparable part of democratic policymaking that fosters citizen beliefs in the legitimacy of a political order and the rightfulness of policy decisions. Policymaking must be publicly justifiable, which can be accomplished through free and uncoerced dialogue between authorities and citizens and among citizens. Being able to have ongoing discussions about disagreements and engage in mutual reason giving in deliberation is essential to a policymaking process aiming to yield just decisions. In ideal situations, deliberation should reflect communicative action, that is, dialogic interactions concerning how to increase mutual understanding among actors.

With a focus on dialogue oriented toward increasing mutual understanding, Habermas $(1984,1990)$ identified two sets of normative conditions under which citizens make sense of procedural justice. Speech conditions form the discursive basis of procedural justice judgments (Renn, Webler \& Wiedemann 1995). This set of conditions holds that deliberations ought to conform to the rules of discourse, which include, 'every subject with the competence to speak and act is allowed to take part in a discourse'; 'everyone is allowed to question any assertion whatever'; 'everyone is allowed to introduce any assertion whatever into the discourse'; 'everyone is allowed to express his attitudes, desires, and needs'; and 'no speaker may be prevented, by internal or external coercion, from exercising his rights' (Habermas, 1990: 89). When individuals feel they or their surrogates can enter a discourse, raise questions freely during discussion, and have equal opportunities to share reasons, they are more likely to acknowledge the rightfulness of a decision-making procedure. These discourse rules that emphasize actors' ability to raise propositions, to enjoy equal opportunities in discourse, and to receive fair consideration of all propositions are aligned with normative theorists' emphasis on equality, reciprocity, accountability, and inclusivity in fair deliberation (Cohen 2009; Gutmann \& Thompson 1996; Young 2002).

Validity conditions constitute the substantive dimension of procedural justicejudgments. Habermas (1979) identified four validity conditions-comprehensibility, truth, appropriateness, and sincerity-with which actors assess each other's communicative orientation toward increasing reciprocal understanding during dialogic interactions. Validity conditions question whether a dialogic process is intelligible (comprehensibility); whether reason giving 
is based on the actors' best knowledge (truth); whether discussion is carried out in an adequate way based on social and cultural expectations (appropriateness); and whether actors truthfully express their genuine intentions during the process (sincerity). As explicated in Communication and the Evolution of Society, the four validity conditions underpin actors' recognition of the communicativeness of their own, as well as others', speech acts:

\begin{abstract}
The speaker must choose a comprehensible expression so that speaker and hearer can understand one another. The speaker must have the intention of communicating a true proposition content... so that the hearer can share the knowledge of the speaker. The speaker must want to express his intentions truthfully so that the hearer can believe the utterance of the speaker (can trust him). Finally, the speaker must choose an utterance that is right so that the hearer can accept the utterance and speaker and hearer can agree with one another in the utterance with respect to a recognized normative background (1979: 2-3).
\end{abstract}

From a Habermasian point of view, procedural justice may originate from discussants' judgments of how well the rules of discourse permit uncoerced reason sharing and policy justification, that is, the perceived fulfillment of ideal speech conditions. When fulfilled, sentiments of procedural justice may emerge from the observation of being able to exercise individuals' political rights in discourse. Alternatively, procedural justice may reflect discussants' collective willingness to gear the conversation toward addressing disagreements and increasing mutual understanding, that is, the perceived fulfillment of validity conditions. The argument made here is that procedural justice does not only demand structural protection for individual rights and opportunities. Procedural justice also demands dialogic interactions in which reason giving, justification of different points of view, and dispute resolution are embedded in the effort to increase reciprocal understanding during deliberation. Speech conditions as the discursive principles of procedural justice reflect the capacity of a procedure to conform to the rules of discourse and to uphold basic liberties and equal rights. This set of conditions focuses on the effective functioning of an argumentation environment that allows uncoerced dialogue to take place (Jacobson \& Storey 2004). Validity conditions, on the contrary, reflect actors' subjective perceptions of each other's communicative orientation based on evaluations of claims to comprehensibility, truth, appropriateness, and sincerity. This set of communicative conditions draws attention to the perceived quality and communicativeness of discussants' speech acts that shape the substantive dimension of procedural justice judgments.

Grounded in normative theories, the communicative action approach is compatible with extant social psychological measures, yet it offers a stronger communicative focus embedded in procedural justice judgments. Table 1 summarizes the compatibility properties of speech conditions and validity conditions. Together, the two sets of communicative norms bridge empirical models' focus on the resource and relational aspects of procedural justice judgments and normative theories' emphasis on the dialogic aspect of procedural justice fulfillment, making them suitable to examine the fulfillment of right and just procedures in deliberative settings.

\section{Outcomes of Fair Deliberative Procedures}

Currently, only a few studies have applied the communicative action approach to test citizens' procedural justice judgments in deliberative decision making. Webler and Tuler (2000) conducted a grounded theory analysis to induce the criteria of procedural fairness and found that the resulting criteria resemble Habermas's communicative norms. Jacobson and Storey (2004) posited that different communicative conditions may yield different significance in different contexts. Yet, overall, they reflect the fairness of a decision-making procedure. Chang and colleagues (Chang \& Jacobson 2010; Chang, Jacobson \& Zhang 2013) examined dialogic interactions between citizens and political authorities in mediated public spheres and found a positive relationship between perceived procedural justice and citizens' beliefs in policy legitimacy. In another study involving deliberation in small groups, Zhang (2015) used the speech condition criteria to evaluate discussants' procedural justice judgments and found that procedural justice was positively associated with enjoyment, satisfaction with group decisions, and intention to engage in future participation. Examination of the substantive dimension of procedural justice was, however, lacking.

To accumulate more evidence on the impact of procedural justice in various deliberative contexts, we conducted a case study involving deliberation in online minipublics to explore the fulfillment and impact of procedural justice in deliberative practices. Specifically, we focused on two policy outcomes-general support for deliberation in policymaking and specific policy supportthat allowed for an examination of potential civic benefits associated with fair deliberation.

\section{General support for deliberative policymaking}

Democratic theorists suggest that well-conducted deliberation can enhance civic virtues such as increased political efficacy, political knowledge, trust, deeper civic engagement in public affairs, and a more informed citizenry (Delli Carpini et al. 2004; Gastil et al. 2002; Grönlund et al. 2010). Good deliberation fosters accountability and legitimacy of policymaking (Cohen 2015; Habermas 1996). Apart from that, deliberation is informative and educational (Fishkin 1991, 2009). Good deliberation is expected to facilitate civic education and political socialization that advance both citizens' knowledge about substantive policy (Fung 2003; Mercier \& Landemore 2012) and their faith in deliberative democracy itself (Benhabib 1996; Cohen 2009; Dryzek 2000). Delli Carpini et al. (2004) reviewed the empirical literature on deliberation and concluded that engaging in deliberation is likely to enhance citizens' sense of empowerment and their beliefs in the basic tenets of deliberative democracy. To highlight the faith-related civic benefits of deliberation, in this study 
Table 1: The compatibility properties of speech and validity conditions.

\begin{tabular}{l} 
Communicative action \\
approach \\
\hline Speech conditions \\
· Ability to raise questions \\
freely during discussion \\
• Equal opportunities to \\
share reasons \\
\\
• Reception of fair treatment \\
and consideration from \\
others \\
Sincerity \\
- Whether actors truth- \\
fully express their genuine \\
intentions \\
Validity conditions- \\
comprehensibility \\
- Whether a deliberative \\
process is comprehensible \\
Truth \\
- Whether the discussion \\
is based on actors' best \\
knowledge \\
Appropriateness \\
carried out in an adequate \\
way based on social and \\
cultural expectations \\
\end{tabular}

Thibaut criteria

Decision control

- Disputants' belief

in their capacity to negotiate for better role positions

Process control

- Perceived equality of opportunities for disputants to present their points of view to the authority

\section{Tyler's relational model of} justice

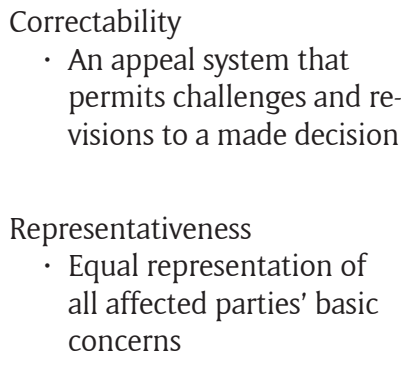

- An appeal system that permits challenges and revisions to a made decision

Representativeness

- Equal representation of all affected parties' basic concerns

Opportunities for participation - Disputants' perceived opportunities to present suggestions about allocative decisions

Treatment with dignity and respect

- The interpersonal quality of the authority's responses to affected parties
Accuracy

- Allocative performance

based on good information

Ethicality

- Adherence of the authority's actions to fundamental moral values accepted by all parties affected by the decisions

Bias suppression

- Efforts by authorities to avoid making allocation decisions based on blind allegiance and self-interest
Neutrality

- The authority's proper and consistent application of rules

Trustworthiness

- Group members' beliefs in the authority's genuine intentions we examine the outcome variable, general support for deliberative decision making, to test its association with procedural justice. We propose that when citizens have an opportunity to participate in fair deliberation, their experience with open dialogue and mutual reason giving should increase their appreciation of the inclusion of deliberation in policymaking and reflect on their support for deliberative policymaking.

\section{Specific policy support}

Besides underpinning citizens' normative support for deliberative democratic processes, past empirical research suggests that good deliberation can restrict extremity in discussants' views on politicians and enhance their acceptance of extant policy (Grönlund et al. 2010; Suiter, Farrell \& O'Malley 2016). Good deliberation resists polarization (Fishkin 2009; List et al. 2013), and when a policy is grounded in reasonableness instead of arbitrary advantages, citizens are more disposed to comply and cooperate with it (Tyler 2000). For instance,
Farrell et al. (2013) found that citizens are more prone to accept tax increases after deliberation. Grönlund et al. (2010) indicated that deliberation enhances discussants' willingness to cooperate with policy decisions. List et al. (2013) noticed that deliberation induces learning and thinking that lead to substantive agreements. Scholars offered explanations that with deliberation, citizens have more opportunities to clarify their views, to gain new information about the policy and compelling reasons for it, to increase the coherence of their beliefs, and to revise their preferences during the discussion process (Farrell et al. 2013; Fishkin 2009; Mercier \& Landemore 2012; Suiter et al. 2016). Curato et al. (2017) concluded that although fair deliberation seldom leads to consensus, it facilitates the production of working agreements and can enhance public empathy for extant policies.

Findings from the past suggest that when procedural fairness is achieved, fair deliberation is likely to persuade participants to accept compelling policy decisions as reasoned social choices. We have, therefore, assumed 
a positive relationship between speech and validity conditions and citizens' specific policy support. Likewise, a fair procedure should strengthen discussants' beliefs in the value of deliberative democracy. Eventually, we raised two hypotheses in this study to test two types of civic benefits ascribed to fair deliberation.

H1: Participants' positive evaluations of (a) speech conditions and (b) validity conditions are associated with their general support for deliberative policymaking.

H2: Participants' positive evaluations of (a) speech conditions and (b) validity conditions are associated with their specific policy support.

\section{Case Study: Deliberation on Singapore's Population Policies}

The case study was an educative forum that involved public discussion on the Singaporean government's population policy. Population issues are a major item on the political agenda in Singapore. The Singaporean government has long been using migration strategies to fuel the growth of its population and economy (Yeoh \& Lam 2016). In 2017 and 2018, foreign migrants constituted $29 \%$ of the overall workforce, and foreign residents and nonresidents accounted for $38 \%$ of the total population of Singapore (Department of Statistics Singapore 2017, 2018; The Strategy Group in the Prime Minister's Office Singapore 2017). In the past decade, a massive inflow of foreigners has created social and cultural issues, such as competition for limited education and housing resources, decreased job opportunities for Singaporeans, and the obliteration of local cultural values, that have led to resistance among citizens (Liu 2014; Teng, Koh \& Soon 2014). Concurrently, the government has enacted Singaporean-centered population policies in response to the aging of the population, low fertility rates, and the urgent need to integrate the influx of foreigners into Singaporean society. These policies include the pronatalist policy, the Fair Consideration Framework (FCF) policy, and the Singapore Citizen Journey (SCJ) program. The pronatalist policy regulates the baby bonus scheme that includes government cash grants for newborns, housing benefits, childcare subsidies, health insurance subsidies, paid maternity leave, and income tax rebates (Saw 2016). The FCF policy encourages companies to hire Singaporeans and develop a 'Singaporean Core' of the workforce (Tripartite Alliance for Fair \& Progressive Employment Practices 2017: 4). The SCJ program is a mandatory program aiming to help new citizens understand Singapore's historical development and deepen their appreciation of Singaporean norms and values (National Integration Council 2017).

The population measures have generated a substantial impact on the workforce, education, child rearing, cultural values, and identity in addition to sparking heated debates about the state's strong intervention in population control (Goh \& Pang 2016; Sun 2012). It has, therefore, become relevant to examine citizens' procedural justice judgments of deliberation in the context of this study.

\section{Methods}

A pre- and postdeliberation survey design was employed in this study. The research data were from an overarching project-Online Deliberation Singapore-conducted by the research team. We developed our own online platform that allowed citizens to participate and deliberate.

The project had three phases: recruitment/predeliberation, deliberation, and postdeliberation. Phase 1 (April 15May 6, 2016) consisted of a national survey with 2,006 Singaporean citizens using panel data. This survey served to explore citizens' attitudes toward the government's population policies before deliberation. Upon completing the survey, respondents were invited to participate in the online deliberation platform and discuss the country's population issues. In total, 1,384 citizens consented to take part in online deliberation, and 510 respondents logged in to the platform at least once. Phase 2 (May 4-May 25, 2016) involved a 3-week period of deliberation dedicated to three topics: the low fertility rate, the high percentage of foreign residents in the workforce, and the social integration of new citizens. The online platform was open 24 hours a day, 7 days a week, and participants could choose to log in and post their views any time they wanted during the project period. Educational slides containing information (e.g., information on population statistics, workforce composition, and population trends) were provided for each topic to stimulate discussion. A trained researcher moderated the deliberations to ensure that the discussions stayed on-topic but did not propose any discussion questions. More information about the platform design and implementation is detailed in the author's previous article (Perrault \& Zhang 2019). Phase 3 (May 27-June 13, 2016) was a postdeliberation survey. Among the 510 users who participated in the online deliberation platform, 456 of them completed this survey. Compared to the census data, participants in the postdeliberation survey were more likely to be male, ethnic Chinese, young, and have higher levels of education and income. The 456 valid cases were used for analysis.

\section{Independent variables}

Two independent variables, speech conditions and validity conditions, were used to measure the discursive and substantive dimensions of procedural justice. Four speech condition items adopted from previous studies (Chang \& Jacobson 2010; Chang et al. 2013; Zhang \& Chang 2014) were modified to measure the degree to which participants felt that they could engage in free and uncoerced dialogue on a 5-point scale ( 1 = strongly disagree; 5 = strongly agree): 'I had full capacity to freely raise questions about the population policies during the discussions'; 'I feel all of us had equal opportunities to express our opinions on the population issues during the discussions'; 'There was good balance in whose opinions about the population issues were being heard during the discussions'; and 'I feel the people I discussed with gave a fair consideration to what I thought about the population issues.' The results of principal component analysis showed that the four items loaded on one factor (Eigenvalue $=2.90$, factor loadings between 0.83 and 0.86 ) and, therefore, they were computed into one combined variable, speech conditions (Cronbach's $\alpha=0.87, M=3.71$, standard deviation $(\mathrm{SD})=0.67$ ). 
On the same rating scale $(1=$ strongly disagree; $5=$ strongly agree), another four validity items were used to measure the extent to which participants recognized other discussants' attempts to increase mutual understanding: 'I think I understand fellow discussants' points about the population issues'; 'I think fellow discussants' opinions about the population issues were based on accurate facts'; 'I think fellow discussants communicated their arguments on the population issues in an appropriate way'; and 'I think fellow discussants expressed their sincere intentions to communicate with me about the population issues.' All items loaded on one factor (Eigenvalue $=2.71$, factor loadings between 0.79 and 0.86 ); hence, they were combined into one variable, validity conditions (Cronbach's $\alpha=0.84, M=3.68, \mathrm{SD}=0.64$ ).

\section{Dependent variables}

This study tested two dependent variables, general support for deliberative policymaking and specific policy support. General support was linked to participants' post hoc evaluation of their deliberative experience and thus was only tested in the postdeliberation survey. Specific policy support was measured in both the preand postdeliberation surveys to permit a comparison. All items measuring the dependent variables were rated on a five-point scale ( 1 = strongly disagree; 5 = strongly agree). General support for deliberative policymaking assessed participants' overall approval of the incorporation of deliberation into political decision-making procedures. It was measured according to three items: 'I feel it is right for citizens to deliberate on taking action to control Singapore's population'; 'I feel citizen deliberation results in just decisions about controlling Singapore's population'; and 'Citizen deliberation as an institution is right and proper' (Cronbach's $\alpha=0.76, M=3.74, \mathrm{SD}=0.63$ ).

Specific policy support assessed the extent to which participants held favorable attitudes toward specific population policies. Three population policies related to pronatalism, the composition of the workforce (i.e., FCF), and the social integration of new citizens (i.e., SCJ) were discussed during deliberation and participants' level of specific support for these specific policies was measured before and after deliberation. Accordingly, three items were used to measure specific policy support: 'I support policies to reduce the cost of having and raising children' (before: $M=4.07, \mathrm{SD}=0.86$; after: $M=3.93, \mathrm{SD}=0.93$ ); 'I support the FCF policy' (before: $M=4.07, \mathrm{SD}=0.86$; after: $M=3.87, \mathrm{SD}=0.88$ ); and 'I support the mandatory Singapore Citizenship Journey' (before: $M=3.79$, SD = 1.04; after: $M=3.65, \mathrm{SD}=0.99$ ). Considering that each item represented a specific dimension of the population policies linked to the country's low fertility rate, high percentage of nonresidents in the workforce, and ways to integrate new arrivals into society, the three items were treated as separate variables instead of as a combined one.

\section{Demographics}

Participants were asked to report their age $(M=39.28$, $\mathrm{SD}=11.56)$, gender $($ male $=58 \%$ ), ethnic background (Chinese $=87 \%$ ), level of education (university and above $=50 \%$ ), and monthly household income (SGD \$8,000 and above $=46 \%$ ). Compared to those who completed the predeliberation survey but did not participate in online deliberation, our participants were more likely to be male and have a higher level of education.

\section{Results}

The hypotheses predicted that participants' positive evaluations of the speech conditions and validity conditions of deliberation can account for their general support for deliberative policymaking (H1) and specific policy support (H2). Zero-order correlations between the predictors and the dependent variables are shown in Table 2.

Table 2: Zero-order correlations between variables.

\begin{tabular}{lcccc} 
& $\begin{array}{l}\text { General support } \\
\text { for deliberation }\end{array}$ & $\begin{array}{c}\text { Support for } \\
\text { pronatalism } \\
\text { (poststudy) }\end{array}$ & $\begin{array}{c}\text { Support } \\
\text { for FCF } \\
\text { (poststudy) }\end{array}$ & $\begin{array}{c}\text { Support for } \\
\text { SCJ } \\
\text { (poststudy) }\end{array}$ \\
\hline Age & 0.07 & $-0.13^{* *}$ & $0.12^{*}$ & 0.08 \\
Male & $0.12^{*}$ & 0.02 & 0.01 & -0.01 \\
Chinese & -0.02 & 0.03 & -0.01 & -0.01 \\
University education & $0.15^{* *}$ & $0.13^{* *}$ & -0.01 & 0.04 \\
Income & -0.02 & -0.05 & 0.04 & 0.05 \\
Speech conditions & $0.70^{* * *}$ & $0.30^{* * *}$ & $0.34^{* * *}$ & $0.37^{* * *}$ \\
Validity conditions & $0.75^{* * *}$ & $0.32^{* * *}$ & $0.34^{* * *}$ & $0.29^{* * *}$ \\
Support for pronatalism (prestudy) & $0.27^{* * *}$ & $0.45^{* * *}$ & $0.21^{* * *}$ & $0.25^{* * *}$ \\
Support for FCF (prestudy) & $0.12^{*}$ & $0.30^{* * *}$ & $0.37^{* * *}$ & $0.31^{* * *}$ \\
Support for SCJ (prestudy) & $0.31^{* * *}$ & $0.29^{* * *}$ & $0.32^{* * *}$ & $0.48^{* * *}$
\end{tabular}

FCF $=$ Fair Consideration Framework; SCJ = Singapore Citizen Journey.

${ }^{*} p<0.01 ;{ }^{* *} p<0.05 ;{ }^{* * *} p<0.001$. 
In this study, different control variables were used to control the effect of procedural justice judgments on general support and specific policy support. Thus, instead of conducting an all-in-one structural equation modeling analysis, we performed hierarchical ordinary least squares regressions for hypothesis testing.

Table 3 summarizes the regression results predicting general support for deliberative policymaking. In block 1, demographics only accounted for a small proportion of the variance in general support. In block 2 , the addition of speech conditions $(\beta=0.30, p<0.001)$ and validity conditions $(\beta=0.51, p<0.001)$ accounted for an additional $56 \%$ of the variance in general support for deliberative decision making (adjusted $R^{2}=0.61, p<0.001 ; \Delta R^{2}=0.56$, $p<0.001)$. Those who considered the discussion process to be well-conducted and those who recognized other people's claims as valid were more likely to support the rightfulness of deliberation in democratic policymaking. H1a and H1b were supported.

$\mathrm{H} 2$ predicted a significant association between participants' assessments of the realization of procedural justice norms and their specific policy support. Before hypothesis testing, paired $t$-tests were performed to examine changes in participants' specific policy support before and after deliberation. A significant decrease in support for the pronatalist policy $(t(438)=3.24, p<0.01)$, the FCF policy $(t(438)=4.50, p<0.001)$, and the mandatory SCJ (t438) $=2.66, p<0.01)$ was found. The results indicated that engaging in deliberation per se did not enhance specific policy support. This finding supported our call to unpack the internal mechanism of deliberation and to focus on the impact of procedural justice judgments.

Table 4 summarizes the results of the regression analyses predicting participants' postdeliberation support

Table 3: Effects of speech and validity conditions on general support for deliberative policymaking.

General support for deliberative policymaking $(\beta)$

\begin{tabular}{lc}
\hline Block 1 & \\
Age & $0.12^{*}$ \\
Male & $0.11^{*}$ \\
Chinese & -0.01 \\
University education & $0.19^{* * *}$ \\
Income & -0.03 \\
$R 2$ change & $0.05^{* * *}$
\end{tabular}

Block 2

$$
\begin{aligned}
& \text { Speech conditions } \\
& \text { Validity conditions } \\
& R^{2} \text { change } \\
& N
\end{aligned}
$$

$0.30^{* * *}$

$0.51^{* * *}$

$0.56^{* * *}$

443

Adjusted $R^{2}$

$0.61^{* * *}$ for each population policy. In each model, participants' predeliberation policy support was controlled to examine the unique effect of speech conditions and validity conditions on specific policy support after deliberation. That is, speech conditions and validity conditions were expected to offer additional explanatory power for predicting participants' postdeliberation policy support, regardless of their initial level of support for specific policies.

Across the regression models, demographics either had a nonsignificant effect on postdeliberation policy support or accounted for a small percentage of the variance in it. It was unsurprising that participants' predeliberation policy support strongly predicted their postdeliberation policy support.

With respect to support for the pronatalist policy, the addition of speech conditions $(\beta=0.13, p<0.05)$ and validity conditions $(\beta=0.08, p>0.05)$ in block 3 accounted for an additional $4 \%$ of the variance in the criterion variable (adjusted $R^{2}=0.25, p<0.001 ; \Delta R^{2}=$ $0.04, p<0.001)$.

With respect to support for the FCF policy, speech conditions $(\beta=0.19, p<0.01)$ had significant predictive power on participants' specific support for this Singaporean-focused workforce policy, but validity conditions $(\beta=0.10, p>0.05)$ did not. These two variables accounted for an additional $7 \%$ of the variance in the criterion variable after all other variables were controlled (adjusted $R^{2}=0.22, p<0.001 ; \Delta R^{2}=0.07, p<0.001$ ).

With respect to support for the mandatory social integration program, participants' specific support could be significantly accounted for by speech conditions $(\beta=$ $0.31, p<0.001)$ but not by validity conditions $(\beta=-0.06$, $p>0.05)$. The addition of speech conditions and validity conditions in the model resulted in a significant increase in the $R^{2}$ and accounted for an additional $6 \%$ of the variance in the criterion variable (adjusted $R^{2}=0.28, p<$ 0.001; $\left.\Delta R^{2}=0.06, p<0.001\right)$.

Overall, speech conditions had a positive effect on participants' specific support for all three population policies. Disregarding their attitudes toward the policies before deliberation, when participants observed that they could freely engage in dialogue and receive fair treatment during discussions, they were more likely to grant their support for the population measures. In contrast, validity conditions had no significant effect on any policy support items in this context. Only $\mathrm{H} 2 \mathrm{a}$ was supported.

\section{Discussion}

This study holds that speech conditions and validity conditions can be used to examine the discursive and substantive dimensions of procedural justice. A review of extant literature demonstrates that the communicative action approach is compatible with extant measures of procedural justice introduced by political psychologists, and yet it has more communication-centered grounds. Moreover, the speech and validity conditions criteria provide broader coverage of the multifaceted fairness principles that deliberative theorists emphasize. While procedural justice may apply in various decision-making processes, this study examines it in the context of an

${ }^{*} p<0.05 ;{ }^{* * *} p<0.001$. 
Table 4: Effects of speech and validity conditions on specific policy support.

\begin{tabular}{lccc} 
& $\begin{array}{c}\text { Support for } \\
\text { pronatalism }(\beta)\end{array}$ & $\begin{array}{c}\text { Support } \\
\text { for FCF }(\beta)\end{array}$ & $\begin{array}{c}\text { Support } \\
\text { for SCJ }(\beta)\end{array}$ \\
\hline Block 1 & $-0.11^{*}$ & $0.13^{*}$ & 0.09 \\
Age & 0.01 & 0.02 & -0.02 \\
Male & -0.01 & 0.02 & 0.01 \\
Chinese & $0.10^{*}$ & 0.02 & 0.06 \\
University education & -0.06 & 0.04 & 0.04 \\
Income & $0.03^{*}$ & 0.02 & 0.01 \\
$R^{2}$ change & & & \\
Block 2 & $0.44^{* * *}$ & - & - \\
Support for pronatalism (pre-study) & - & $0.39^{* * *}$ & - \\
Support for FCF (pre-study) & - & - & $0.47^{* * *}$ \\
Support for SCJ (pre-study) & $0.19^{* * *}$ & $0.15^{* * *}$ & $0.22^{* * *}$ \\
$R^{2}$ change & & & \\
Block 3 & $0.13^{*}$ & $0.19^{* *}$ & $0.31^{* * *}$ \\
Speech conditions & 0.08 & 0.10 & -0.06 \\
Validity conditions & $0.04^{* * *}$ & $0.07^{* * *}$ & $0.06^{* * *}$ \\
$R^{2}$ change & 441 & 441 & 437 \\
$N$ & $0.25^{* * *}$ & $0.22^{* * *}$ & $0.28^{* * *}$ \\
Adjusted $R^{2}$ & & &
\end{tabular}

FCF = Fair Consideration Framework; SCJ = Singapore Citizen Journey.

${ }^{*} p<0.05$; $^{* *} p<0.01 ;{ }^{* * *} p<0.001$.

online deliberation forum to highlight the need for quality deliberation to meet discourse norms and validity conditions to be considered fair and just. The associated outcomes are civic benefits derived from fair deliberation that include beliefs in the rightfulness of deliberative democracy and citizens' proneness to social cooperation.

The results of the case study indicate that speech conditions have consistent predictive significance on both general support for deliberative policymaking and specific policy support. Contrarily, validity conditions are only associated with general support for deliberative decision making. The discursive and substantive dimensions of procedural justice are prioritized in different ways when evaluating the relationship between fair deliberation and citizen support at the general and specific levels in the context that was studied.

The finding of a significant relationship between both speech and validity conditions and general support for deliberative policymaking illustrates how the fulfillment of procedural justice can foster citizen beliefs in deliberative democracy. When speech conditions are satisfied, they reflect a healthy discourse that allows discussants to freely raise agendas, clarify doubts, and receive fair consideration and respect from others. Likewise, when validity conditions are satisfied, they reflect the communicative orientation of the discussion process. Our findings indicate that a positive experience with fair deliberation is likely to enhance citizens' recognition of the normative value of deliberative democracy. This finding corresponds to past research's notion that good deliberation could provide civic education and enhance discussants' appreciation of the deliberative core of democratic policymaking (Gastil et al. 2002; Fishkin 2009; Zhang 2015). When fair deliberation allows discussants to experience reason giving with an orientation toward increasing mutual understanding, it also offers a learning opportunity for discussants to deepen their understanding of the normative importance of deliberative democracy. The educative value of fair deliberation is supported in this study.

On the contrary, procedural justice holds a complex relationship with specific policy support in the present study. A decrease in participants' specific policy support was found after deliberation. At first glance, this finding may differ from previous empirical works stating that deliberation can reduce extremity in beliefs and induce more agreements on extant policy (Farrell et al. 2013; Grönlund et al. 2010; List et al. 2012; Suiter, Farrell \& O'Malley 2016), yet this very finding resonates with our argument that a mere yes or no measure of deliberation is insufficient to elucidate the connection between good deliberation and civic benefits. The decreased policy support shown in paired $t$ tests and the positive association between speech conditions and policy support illustrate that deliberation is likely to shift public opinions toward more favorable ones only when the discussion process is perceived to be fair and just. Specifically, the discursive dimension of procedural 
justice judgments plays a more critical role than the substantive dimension in predicting citizens' granting of policy support. This finding demonstrates the importance of going beyond examining the inclusion or exclusion of deliberation in political decision making and testing the internal mechanism of deliberation that underlies why actors' deliberative experiences are associated with their willingness to cooperate. Deliberative theorists have argued that accountability is the bedrock of policy legitimacy (Cohen 2015; Dryzek 2000; Habermas 1996) and accountability is built upon citizens' perceived capacity to justify the reasonableness of political decisions (Delli Carpini et al. 2004). The direct test of speech conditions answers questions regarding how well public justification and reason giving are protected in discourse. This finding of a positive association between speech conditions and policy support illustrates the possibility of generating a more cooperative citizenry through open dialogue. The empirical evidence puts the informative benefits of fair deliberation in perspective and sheds light on the proceduralist standards based on which citizens grant support to policy decisions.

Notably, validity conditions have a nonsignificant relationship with specific policy support in this study. The results seemingly contradict the relational model of justice, which holds that relational judgments such as neutrality, trustworthiness, and status recognition are more critical than the amount of control individuals enjoy during decision making in accounting for policy acceptance (Lind \& Tyler 1988; Tyler 1988, 2000). The results of the present study also differ from past research using the communicative action approach that found a positive relationship between validity conditions and citizens' beliefs in policy legitimacy (Chang \& Jacobson 2010; Chang et al. 2013). The inconsistent results may be due to the different parties with which citizens deliberate.

When interacting with the government, which has the final say in policy decisions, citizens may prioritize the government's perceived communicative orientation and its pursuit of mutual understanding as the most important criteria of fair deliberation. Accordingly, the substantive dimension of procedural justice is likely to be highlighted in government-led discussions and hearings to predict citizen support. In contrast, as the present study illustrates, the fulfillment of speech conditions may be more critical to deliberation among citizens in that support for specific policy is grounded in citizens' perceived capacity to engage in reason sharing and public justification. The incoherent empirical evidence suggests that variations may exist in different deliberative performances in which different parties are involved and different decision-making goals are pursued. This is also aligned with Jacobson and Storey's (2004) notion that certain speech and validity conditions may be thematized in different deliberative contexts. Although validity conditions show limited influences on specific policy support in the present study, they may link to other relational outcomes associated with fair deliberation in other contexts. Research may continue exploring other deliberative benefits directly associated with this dimension of procedural justice in the future.

\section{Implications and Limitations}

As the online deliberation forum was created by the research team, findings from this study have some practical implications for forum improvement that may enhance procedural justice from the perspective of design. This study illustrates the benefits of improving discussants' appraisals of speech conditions and validity conditions, which ultimately link to positive deliberative outcomes.

To improve speech conditions, future forum designers may consider providing clearer instructions about fair discussion rules at the beginning of each online deliberation session. Moderators could take on more responsibility to remind participants of the rules of fairness. An incentive mechanism could be built to reward behaviors consistent with principles of justice. All these options offer directions for future innovative design and the testing of forum effectiveness.

Validity conditions are more difficult to alter because they are anchored in discussants' subjective feelings about each other's communicative orientation, which is beyond what a good design can affect. The key to improved fairness thus becomes equipping individuals with the right resources and tools to encourage them to make valid claims and to have the ability to easily assess other actors' propositions. The forum design could, for instance, include cues that allow users to express themselves more clearly, accurately, appropriately, and sincerely. The interface should be designed to ease participants' comprehension and evaluation of other discussants' validity claims. Another design consideration might be to provide educational material that not only informs readers about the issues to be discussed but illustrates how and why the issues are worth discussing using reciprocal reason giving based on validity norms. That is, educational material could serve an informative function to increase participants' willingness to be more communicative (e.g., tell the truth and be sincere) when engaging in deliberation.

Three limitations should be taken into account when interpreting the results of this study. First, in this study we did not create a control group in which participants did not experience the deliberation treatment. We had two reasons for not doing so. First, considering that all citizens' opinions were important, we felt hesitant to recruit a control group that deprived participants of their opportunity to deliberate. Second, as this study focused on discussants' perceptions of the deliberative discourse and the evaluation of their deliberative experience, those who did not go through any deliberation activities would not be able to respond to the measures. We, however, acknowledge that differences between those who deliberated and those who did not may have potential impacts on the changes in their policy support. Future research should address issues regarding the design of a control group to permit difference-indifference estimation and enhance the explanatory power of the findings.

The second limitation of this study is that we did not compare differences between active and passive participants because the focus was on perceptions of 
procedural justice and deliberative outcomes. From a theoretical perspective, procedural justice judgments need not be associated with frequency of comments or intensity of online interactions. Whether vocal or observant, participants are eligible to evaluate whether the structural environments protect their rights to speak if they want to and whether they believe in others' intention to increase mutual understanding. Having said this, linking measures of participant activeness to survey data may offer more insights into discussants' deliberative experiences and their perceptions of procedural justice. Future research should explore these possibilities.

Third and finally, the high correlation between validity conditions and general support alludes to the problem of multicollinearity. Although similar measures have been tested in previous studies that established validity and reliability (Chang et al. 2013; Chang \& Jacobson 2010), findings from this study indicate a need to further improve the research design. More empirical research is needed to validate the analytical framework.

\section{Conclusion}

In conclusion, this study reviews extant conceptualizations of what is considered a fair procedure and introduces a communicative action approach for evaluating procedural justice in deliberation. The literature review and the case study shed light on how procedural justice can be theorized and measured with a stronger focus on communication. By unpacking the internal mechanism of deliberation from the perspective of procedural justice, this study contributes to advancing the understanding of when quality deliberation is achieved and what benefits fair deliberation can yield. As the results point out, deliberation might not always lead to increased policy support. Fair deliberation nevertheless makes it possible to allow for reason sharing, policy justification, and a better understanding of diverse points of view among those who are affected by the policy decisions. These practices are important steps in enhancing citizens' support for specific policies to be deliberated on, and at a more fundamental level, forming the basis of public approval of the rightfulness of deliberation in democracies. Online deliberation initiatives should strive to foster such practices using innovative and effective design.

\section{Funding Information}

The project was funded by Singapore Ministry of Education Academic Research Fund Tier 2 (Ref No. MOE2013-T2-1-105).

\section{Competing Interests}

The authors have no competing interests to declare.

\section{References}

Benhabib, S. (1996). Toward a deliberative model of democratic legitimacy. In S. Benhabib (Ed.), Democracy and difference: Contesting the boundaries of the political (pp. 67-94). Princeton, NJ: Princeton University Press.
Besley, J. C. (2010). Public engagement and the impact of fairness perceptions on decision favorability and acceptance. Science Communication, 32(2), 256-280.

Besley, J. C., \& McComas, K. A. (2005). Framing justice: Using the concept of procedural justice to advance political communication research. Communication Theory, 15(4), 414-436.

Birnbaum, S., Bodin, Ö., \& Sandström, A. (2015). Tracing the sources of legitimacy: The impact of deliberation in participatory natural resource management. Policy Sciences, 48, 443-461.

Bradford, B. (2011). Voice, neutrality and respect: Use of victim support services, procedural fairness and confidence in the criminal justice system. Criminology \& Criminal Justice, 11(4), 345-366.

Burdziej, S., Guzik, K., \& Pilitowski, B. (2019). Fairness at trial: The impact of procedural justice and other experiential factors on criminal defendants' perceptions of court legitimacy in Poland. Law \& Social Inquiry, 44(2), 359-390.

Chambers, S. (2003). Deliberative democratic theory. Annual Review of Political Science, 6, 307-326.

Chang, L., \& Jacobson, T. (2010). Measuring participation as communicative action: A case study of citizen involvement in and assessment of a city's smoking cessation policy-making process. Journal of Communication, 60(4), 660-679.

Chang, L., Jacobson, T. L., \& Zhang, W. (2013). A communicative action approach to evaluating citizen support for a government's smoking policies. Journal of Communication, 63(6), 1153-1174.

Cohen, J. (1993). Pluralism and proceduralism. ChicagoKent Law Review, 69(3), 589-618.

Cohen, J. (2009). Philosophy, politics, democracy: Selected essays. Cambridge, MA: Harvard University Press.

Cohen, J. (2015). Deliberation and democratic legitimacy. In J. Bohman \& W. Rehg (Eds.), Deliberative democracy: Essays on reason and politics (pp. 67-91). Cambridge, MA: MIT Press.

Colquitt, J. A. (2001). On the dimensionality of organizational justice: A construct validation of a measure. Journal of Applied Psychology, 86(3), 386-400.

Colquitt, J. A., Conlon, D. E., Wesson, M. J., Porter, C. O. L. H., \& Ng, K. Y. (2001). Justice at the Millennium: A meta-analysis review of 25 years of organizational justice research. Journal of Applied Psychology, 86(3), 425-445.

Curato, N., Dryzek, J. S., Ercan, S. A., Hendriks, C. M., \& Niemeyer, S. (2017). Twelve key findings in deliberative democracy research. Daedalus, the Journal of the American Academy of Arts \& Sciences, 146(3), 28-38.

Delli Carpini, M. X., Cook, F. L., \& Jacobs, L. R. (2004). Public deliberation, discursive participation, and citizen engagement: A review of the empirical literature. Annual Review of Political Science, 7, 315344.

Department of Statistics Singapore. (2017). Population trends, 2017. Retrieved from https://www.singstat. gov.sg/-/media/files/publications/population/ population2017.pdf. 
Department of Statistics Singapore. (2018). Population trends, 2018. Retrieved from https://www.singstat. gov.sg/-/media/files/publications/population/ population2018.pdf.

Dryzek, J. S. (2000). Deliberative democracy and beyond: Liberals, critics, contestations. New York: Oxford University Press.

Farrell, D. M., O'Malley, E., \& Suiter, J. (2013). Deliberative democracy in action Irish-style: The 2011 We the Citizens pilot citizens' assembly. Irish Political Studies, 28(1), 99-113.

Fishkin, J. S. (1991). Democracy and deliberation: New directions for democratic reform. New Haven, CT: Yale University Press.

Fishkin, J. S. (2009). When the people speak: Deliberative democracy \& public consultation. Oxford: Oxford University Press.

Fung, A. (2003). Survey article: Recipes for public spheres: Eight institutional design choices and their consequences. Journal of Political Philosophy, 11(3), 338-367.

Gastil, J., Deess, E. P., \& Weiser, P. (2002). Civic awakening in the jury room: A test of the connection between jury deliberation and political participation. The Journal of Politics, 64(2), 585-595.

Goh, D., \& Pang, N. (2016). Protesting the Singapore government: The role of collective action frames in social media mobilization. Telematics and Informatics, 33(2), 525-533.

Gopinath, C., \& Becker, T. E. (2000). Communication, procedural justice, and employee attitudes: Relationships under conditions of divestiture. Journal of Management, 26(1), 63-83.

Grimes, M. (2006). Organizing consent: The role of procedural fairness in political trust and compliance. European Journal of Political Research, 45(2), 285-315.

Grönlund, K., Setälä, M., \& Herne, K. (2010). Deliberation and civic virtue: Lessons from a citizen deliberation experiment. European Political Science Review, 2(1), 95-117.

Gutmann, A., \& Thompson, D. (1996). Democracy and disagreement: Why moral conflict cannot be avoided in politics, and what can be done about it. Cambridge, MA: Harvard University Press.

Gutmann, A., \& Thompson, D. (2004). Why deliberative democracy? Princeton, NJ: Princeton University Press.

Haas, N. E., Van Craen, M., Skogan, W. G., \& Fleitas, D. M. (2015). Explaining officer compliance: The importance of procedural justice and trust inside a police organization. Criminology \& Criminal Justice, 15(4), 442-463.

Habermas, J. (1979). Communication and the evolution of society. Boston, MA: Beacon.

Habermas, J. (1984). The theory of communicative action, volume 1: Reason and the rationalization of society. Boston, MA: Beacon.

Habermas, J. (1990). Moral consciousness and communicative action. Cambridge, MA: MIT Press.

Habermas, J. (1991). The structural transformation of the public sphere: An inquiry into a category of bourgeois society. Cambridge, MA: MIT press.
Habermas, J. (1996). Between facts and norms: Contributions to a discourse theory of law and democracy. Cambridge, MA: MIT Press.

Herian, M. N., Hamm, J. A., Tomkins, A. J., \& Pytlik Zillig, L. M. (2012). Public participation, procedural fairness, and evaluations of local governance: The moderating role of uncertainty. Journal of Public Administration Research and Theory, 22(4), 815-840.

Hollander Blumoff, R., \& Tyler, T. R. (2008). Procedural justice in negotiation: Procedural fairness, outcome acceptance, and integrative potential. Law \& Social Inquiry, 33(2), 473-500.

Jacobson, T. L., \& Storey, J. D. (2004). Development communication and participation: Applying Habermas to a case study of population programs in Nepal. Communication Theory, 14(2), 99-121.

Leventhal, G. S. (1980). What should be done with equity theory? New approaches to the study of fairness in social relationships. In K. J. Gergen, M. S. Greenberg, \& R. H. Willis (Eds.), Social exchange (pp. 27-55). Boston, MA: Springer.

Lind, E. A., \& Tyler, T. R. (1988). The social psychology of procedural justice. New York: Plenum Press.

List, C., Luskin, R. C., Fishkin, J. S., \& McLean, I. (2012). Deliberation, single-peakedness, and the possibility of meaningful democracy: Evidence from deliberative polls. The Journal of Politics, 75(1), 80-95.

Liu, H. (2014). Beyond co-ethnicity: The politics of differentiating and integrating new immigrants in Singapore. Ethnic and Racial Studies, 37(7), 12251238.

Mansbridge, J., et al. (2012). A systemic approach to deliberative democracy. In J. Parkinson \& J. Mansbridge (Eds.), Deliberative systems: Deliberative democracy at the large scale (pp. 1-26). New York: Cambridge University Press.

Mazerolle, L., Antrobus, E., Bennett, S., \& Tyler, T. R. (2013). Shaping citizen perceptions of police legitimacy: A randomized field trial of procedural justice. Criminology, 51(1), 33-63.

McCarthy, T. (1994). Kantian constructivism and reconstructivism: Rawls and Habermas in dialogue. Ethics, 105(1), 44-63.

Mercier, H., \& Landemore, H. (2012). Reasoning is for arguing: Understanding the successes and failures of deliberation. Political Psychology, 33(2), 243-258.

Murphy, K., \& Tyler, T. (2008). Procedural justice and compliance behaviour: The mediating role of emotions. European Journal of Social Psychology, 38(4), 652-668.

National Integration Council. (2017). Singapore citizenship journey. Retrieved from https://www. nationalintegrationcouncil.org.sg/citizenship/ singapore-citizenship-journey.

Owen, D., \& Smith, G. (2015). Survey article: Deliberation, democracy, and the systemic turn. Journal of Political Philosophy, 23(2), 213-234.

Perrault, S. T., \& Zhang, W. (2019). Effects of moderation and opinion heterogeneity on attitude towards the online deliberation experience. Proceedings of the 2019 CHI Conference on Human Factors in Computing 
Systems (p. 17). ACM. Retrieved from https://arxiv.org/ pdf/1901.10720.pdf.

Rawls, J. (1999). A theory of justice(revised ed.). Cambridge, MA: Harvard University Press.

Reisig, M. D., Tankebe, J., \& Mesko, G. (2014). Compliance with the law in Slovenia: The role of procedural justice and police legitimacy. European Journal on Criminal Policy and Research, 20, 259-276.

Renn, O., Webler, T., \& Wiedemann, P. (Eds.). (1995). Fairness and competence in citizen participation: Evaluating models for environmental discourse. Dordrecht: Kluwer Academic Publishers.

Saw, S.-H. (2016). Population policies and programmes in Singapore. Singapore: ISEAS Publishing.

Strategy Group in the Prime Minister's Office Singapore. (2017). Population in brief 2017. Retrieved from https:// www.strategygroup.gov.sg/docs/default-source/defaultdocument-library/population-in-brief-2017.pdf.

Suiter, J., Farrell, D. M., \& O'Malley, E. (2016). When do deliberative citizens change their opinions? Evidence from the Irish Citizens' Assembly. International Political Science Review, 37(2), 198-212.

Sun, S. (2012). Population policy and reproduction in Singapore: Making future citizens. London: Routledge.

Teng, Y. M., Koh, G., \& Soon, D. (Eds.). (2014). Migration and integration in Singapore: Policies and practice. London, UK: Routledge.

Thibaut, J., \& Walker, L. (1978). A theory of procedure. California Law Review, 66(3), 541-566.

Thibaut, J., Walker, L., LaTour, S., \& Houlden, P. (1974). Procedural justice as fairness. Stanford Law Review, 26(6), 1271-1289.

Tripartite Alliance for Fair \& Progressive Employment Practices. (2017). Tripartite guidelines on fair employment practices. Retrieved from https:// www.tafep.sg/sites/default/files/Tripartite $\% 20$ Guidelines\%20on\%20Fair\%20Employment\%20 Practices_20170310_Eng.pdf.

Tyler, T. R. (1988). What is procedural justice? Criteria used by citizens to assess the fairness of legal procedures. Law \& Society Review, 22(1), 103-135.

Tyler, T. R. (1994). Psychological models of the justice motive: Antecedents of distributive and procedural justice. Journal of Personality and Social Psychology, 67(5), 850-863.

Tyler, T. R. (1997). The psychology of legitimacy: A relational perspective on voluntary deference to authorities. Personality and Social Psychology Review, 1(4), 323-345.

Tyler, T. R. (2000). Social justice: Outcome and procedure. International Journal of Psychology, 35(2), 117-125.

Webler, T., \& Tuler, S. (2000). Fairness and competence in citizen participation: Theoretical reflections from a case study. Administration \& Society, 32(5), 566595.

Yeoh, B. S., \& Lam, T. (2016). Immigration and its (dis) contents: The challenges of highly skilled migration in globalizing Singapore. American Behavioral Scientist, 60(5-6), 637-658.

Young, I. M. (2002). Inclusion and democracy. New York: Oxford University Press.

Zhang, W. (2015). Perceived procedural fairness in deliberation: Predictors and effects. Communication Research, 42(3), 345-364.

Zhang, W., \& Chang, L. (2014). Perceived speech conditions and disagreement of everyday talk: A proceduralist perspective of citizen deliberation. Communication Theory, 24(2), 124-145.

\footnotetext{
How to cite this article: Chang, L., \& Zhang W. (2021). Procedural Justice in Online Deliberation: Theoretical Explanations and Empirical Findings. Journal of Deliberative Democracy, 17(1), pp.105-117. DOl: https://doi.org/10.16997/jdd.968
}

Submitted: 6 February 2019 Accepted: 12 May $2020 \quad$ Published: 28 April 2021

Copyright: ( $) 2021$ The Author(s). This is an open-access article distributed under the terms of the Creative Commons Attribution 4.0 International License (CC-BY 4.0), which permits unrestricted use, distribution, and reproduction in any medium, provided the original author and source are credited. See http://creativecommons.org/licenses/by/4.0/. 